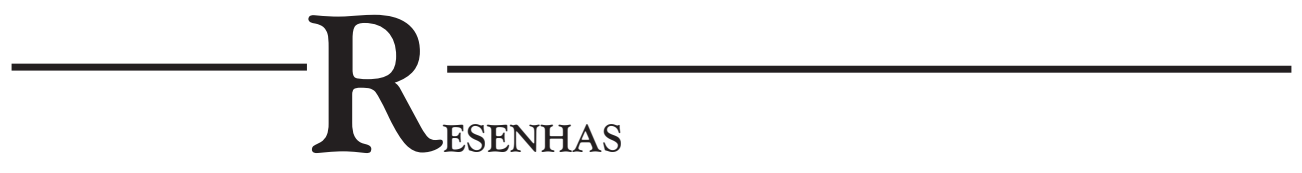

TEIXEIRA, Jacqueline Moraes. A Mulher Universal: Corpo, Gênero e Pedagogia da Prosperidade. Rio de Janeiro: Mar de Ideias, 2016, 216pp.

\title{
Prosperidade e gênero na Igreja Universal do Reino de Deus
}

\author{
Wallace Cabral Ribeiro \\ Universidade Federal Fluminense - Niterói \\ Rio de Janeiro - Brasil
}

O livro A Mulher Universal, de Jacqueline Teixeira, traz novas e potentes contribuições para o campo de pesquisa sobre pentecostalismo no Brasil. $\mathrm{O}$ recorte de gênero é um dos pontos de destaque dessa pesquisa, alvo também de outras produções da autora. $O$ ponto de partida da obra é a discussão sobre as posições polêmicas de algumas lideranças iurdianas no que se refere ao apoio à legalização do aborto. Para Teixeira, essas posições não têm como elemento central o proselitismo ou a polarização da IURD em relação à Igreja Católica, uma das razões que fundamenta esses posicionamentos seria a teologia da prosperidade. Dentro dessa perspectiva, é imputada às mulheres uma maior responsabilidade pelo alcance da prosperidade, uma vez que elas seriam a espinha dorsal da harmonia conjugal e familiar. A autora destaca que "a prosperidade na IURD não se restringe apenas ao âmbito financeiro 
representado pelo dinheiro" (: 97), mas à harmonia "em todas as instâncias da vida, sendo a família a principal delas" (Ibidem).

No primeiro capítulo, Teixeira aglutina suas reflexões sobre direito reprodutivo, gênero e prosperidade na Igreja Universal observando atentamente as declarações proferidas pelo Bispo Edir Macedo sobre esses temas. Para Macedo, filhos não planejados podem comprometer a qualidade de vida da família, além disso, uma criança indesejada poderia ser a causa de males sociais. Desse modo, o aborto configura-se como um "método contraceptivo, lido na chave do controle da pobreza" (: 86).

"O aborto deixa de ser visto como uma atitude individual, praticado por uma mulher egoísta que prefere a si em detrimento de uma criança, e passa ser visto como uma ação de caráter coletivo" (: 189). Nesse sentido, o aborto é compreendido como um "bem social, que se faz para se controlar os problemas sociais privilegiando o bem-estar de um coletivo" (: 194). Um dos pensadores mobilizados pela autora é Habermas, com o conceito de "esfera pública", compreendido "como um espaço constituído por meio da ação comunicativa (...), a esfera de formulação e publicização de discursos (...), [uma vez que] a linguagem é compreendida como ação" (: 35). Nesse sentido, Teixeira entende que é pela "ação comunicadora", promovida pelos agentes iurdianos sobre a questão do aborto numa perspectiva de prosperidade, que emerge um discurso que visa conformar "uma opinião pública" (: 36).

No segundo capítulo, Teixeira aborda as práticas sacrificiais, os rituais, o corpo feminino performando sacrifícios cotidianos, a divisão sexual do trabalho eclesiástico, além de uma série de elementos expressivos constituintes do casamento. Ao longo de todo o livro, a autora não enfatiza o "imediatismo" como questão central para compreensão da chamada Teologia da Prosperidade, tal como fazem inúmeros autores. Na perspectiva de Teixeira, trata-se do estabelecimento de uma pedagogia da prosperidade, algo que está para além de práticas religiosas que produziriam resultados imediatos na vida do fiel. O jornal Folha Universal, o projeto Godllywood, o curso Casamento Blindado, o programa televisivo The Love School, as reuniões da Terapia do Amor, entre outros, são recursos institucionais que compõem a pedagogia da prosperidade. Uma educação que se expressa sistematicamente na cotidianidade através de um conjunto de métodos que asseguraria uma formação teológica voltada à prosperidade. A autora traz para sua análise o conceito de "habitus", de Bourdieu, empregado no sentido de que as ações e argumentos da cosmovisão iurdiana são "uma disposição mental de apreensão do mundo" (: 40), "uma disposição prática determinada por variáveis como classe social, época histórica, cultura, entre outros" (: 41). Nesse sentido, a pedagogia da prosperidade é uma "disposição mental de apreender o mundo" (: 40), tendo o feminino como uma variável determinante desse conjunto de práticas sociais.

De acordo com Teixeira, o "direito de prosperidade está diretamente relacionado ao sacrifício" (: 127). A pedagogia da prosperidade ajuda a "educar o desejo, para somente depois desprender-se em sacrifício" (Ibidem). Nesse sentido, o sacrifí- 
cio é o grande intermediador de conquistas, das financeiras às emocionais. $O$ testemunho de Deusa, uma ex-moradora de rua desempregada, exemplifica a articulação entre sacrifício e prosperidade. Ao entrar em uma filial da IURD em busca de auxílio, o pastor lhe entregou um envelope orientando-a a fazer um sacrifício monetário. Apesar de impactada com a situação, Deusa aceita o desafio proposto. Ela se emprega em um bar, economiza dinheiro e o entrega à IURD em forma de sacrifício. Após esse episódio, sua condição de vida se transforma tão plenamente que ela "passa de desempregada para empregada e de empregada para empregadora” (: 136).

Deusa sacrificou aquilo que mais lhe fazia falta, o dinheiro, porém, como destaca Teixeira, "o exercício da poupança não se baseia no valor excedente, mas, ao contrário, o poupador disciplinado poupa, inclusive, em condição de escassez" (: 135). "O desafio da entrega em sacrifício do bem poupado se assemelha ao desafio de se começar o próprio empreendimento" (: 137).

No testemunho de Deusa, "sua situação como mendiga parece se afirmar na descrição do seu corpo: o odor, a sujeira, as roupas rasgadas emergem como marcadores de sua condição de pecadora e de seu distanciamento de Deus" (: 136). Para Teixeira, o corpo é um dos "dispositivos facilitadores da relação que se estabelece entre o fiel e Deus" (: 138), no caso das mulheres, é um "dispositivo central".

A partir dessa concepção, o projeto Godllywood foi criado com o objetivo de ensinar mulheres a "serem mulheres". As participantes são educadas a se tornarem vigilantes do próprio corpo, a partir de uma concepção foucaultiana de "cuidado de si”. A autora identifica nessa prática iurdiana "uma cultura de si", ou seja, um conjunto de práticas que tem como alvo a disciplinarização do corpo. O "cuidado de si" se engendra no cuidado para com o outro, "o gerenciamento do corpo da mulher se desdobra de modo a gerenciar outros corpos, na medida em que a mulher é interpretada como centro da vida familiar" (Op. cit.: 149).

Os desafios lançados pelo Godllywood as suas participantes consistem em cuidar da aparência, cozinhar, acordar mais cedo, ler a Bíblia, ficar sem consumir carne vermelha por algum tempo, demonstrar afeto aos familiares etc. $\mathrm{Na}$ "realização de pequenos sacrifícios cotidianos, passa a incorporar o sagrado como estilo de vida" (: 158). Nesse sentido, Teixeira entende que "produzir dispositivos para apreensão do torna-se mulher emerge como chave organizadora do cotidiano" (:162, grifos da autora).

Outro fator interessante é a divisão sexual do trabalho na IURD, marcada pela divisão geográfica entre o átrio e o altar, que são "espaços de diferenciação entre os sexos" (: 141). As mulheres em geral ficam no átrio e os homens no altar. Somente o casamento viabiliza a ascensão das mulheres na hierarquia sacerdotal, "sem um marido atuante no altar, a mulher só pode aspirar ao posto de obreira” (: 140). Além disso, as mulheres do altar estão aptas a se dirigirem apenas ao público feminino (: 147).

O terceiro capítulo da obra discute a vida conjugal e os papéis de cada sexo para se alcançar a prosperidade. O matrimônio "deve ser o quesito principal na vida dos indivíduos" (: 169), que, todavia, deve constituir-se segundo uma lógica empre- 
sarial, estruturando-se em dois princípios fundamentais: objetivos e resultados. As escolhas para uma união matrimonial devem ser racionais e não emocionais, atentando para fatores como cor, idade e compatibilidade profissional, ou seja, uma série de elementos que favoreçam um casamento próspero.

É necessário um conjunto de combinações para o sucesso matrimonial à prova de divórcio, tais como: razão, amor, inteligência, homem líder, mulher submissa, entre outros. Uma combinação de elementos opostos a esses produz um casamento fracassado, tendo como resultado o divórcio. A "fé racional se apresenta como condição indispensável para o êxito no casamento" (: 182).

A Terapia do Amor é uma reunião voltada especificamente a relacionamentos heteroafetivos. Um espaço para contrair matrimônio e para a "restauração" de casamentos. Com base nesses objetivos, a Terapia do Amor, como descreve Teixeira, facilita o encontro entre pessoas de sexo oposto e realiza rituais de despossessão demoníaca para "restaurar" casamentos infelizes. O programa televisivo The Love School é voltado para a vida conjugal e se estrutura na exibição de depoimentos gravados por casais que vivenciam algum conflito. Intermitentemente, "os apresentadores-professores Cris e Renato pausam a imagem e comentam os pontos do conflito propondo maneiras para se amenizar as situações" (: 175). Tanto a Terapia do Amor quanto o The Love School são projetos disciplinares voltados para o casamento que incidem sobre os sujeitos introduzindo novas formas de conceber a relação matrimonial baseada em escolhas racionais.

Enfim, a obra apresenta uma importante contribuição sobre noções e comportamentos que se propõem a orientar as escolhas cotidianas dos frequentadores e frequentadoras da IURD, mas visam à sociedade como um todo. Como o aborto é um tema de suma importância na análise da autora sobre gênero e religião no contexto iurdiano, o trabalho se beneficiaria com um maior aprofundamento sobre o processo de criminalização do aborto no Brasil, trazendo mais dados históricos que revelem suas múltiplas determinações, como, por exemplo, as influências de forças religiosas protestantes na história recente (dos últimos 30 anos) da criminalização do aborto. Também se enriqueceria com uma maior contextualização histórica sobre a influência do pensamento positivista na formação da laicidade do Estado Republicano, bem como uma breve análise sociológica sobre qual lugar a Igreja Católica ocupava na sociedade e seu posicionamento em relação ao Estado Monárquico, e quais perdas teriam culminado no seu afastamento relativo junto ao poder público. Também poderia aprofundar a contextualização bíblica sobre o que fundamenta a concepção teológica de "mulher virtuosa" nos discursos iurdianos. A Mulher Universal, de Jacqueline Teixeira, é uma obra de grande importância nos estudos sobre religião e gênero nas Ciências Sociais contemporâneas. 
Wallace Cabral Ribeiro (cabralwallaceribeiro@yahoo.com.br) Mestrando do Programa de Pós-graduação em Sociologia da Universidade Federal Fluminense (PPGS-UFF), bacharel em Sociologia pela mesma instituição, editor da Revista Ensaios, membro do Núcleo de Estudo Friedrich Engels (NEFE) e do Núcleo de Estudos Cidadania, Trabalho e Arte (Nectar-UFF). 